\title{
Dermoid Cysts of the Anterior Fontanel in Adults
}

Ramnarayan $\mathbf{R}^{*}$ and Dharmendra KR

${ }^{1}$ Visiting Consultant Neurosurgeon, Al Hayat

International Hospital, Muscat

${ }^{2}$ Consultant Surgeon, Kaveri Hospital, India

*Corresponding author: Ramnarayan R, Visiting

Consultant Neurosurgeon, Al Hayat International

Hospital, Muscat

Received: November 16, 2017; Accepted: December 12, 2017; Published: December 19, 2017

\section{Introduction}

Dermoid cysts are benign cystic lesions that occur at lines of fusion in the body. Dermoid cysts of the scalp including at the anterior fontenelle in infants and small children have been reported in the literature [1-3]. But not many reports exist on this condition in adults. Here we present three adults who presented with this condition.

\section{Case Reports}

\section{Case 1}

The first patient was a $27 \mathrm{yr}$ old young man who noticed this swelling about seven years before. He noticed this when he started getting hurt while combing his hair. Clinical examination (Figure 1) revealed a well rounded swelling of about $3 X 3 \mathrm{~cm}$ size in the region of the anterior fontenelle. There were no visible pulsations, any sinus tract or punctum or dilated veins seen. On examination the lesion had heterogenous consistency with some areas soft and cystic. It was not tender and non pulsatile and did not give a cough impulse. Transillumination was not present and there was no bruit on auscultation. The bony margins were felt to be inverted.

\section{Case 2}

This was a eighteen year old boy who underwent tonsuring of the head and the noticed this swelling of around $1.5 \mathrm{~cm}$ with a punctum (Figure 2). The other findings were similar. There was no discharge from the punctum.

\section{Case 3}

In this 22 year old young lady the beautician noticed this swelling with similar findings but no punctum.

All the patients underwent CT scans which showed a no intracranial extension in any case. MRI was done in all cases and intracranial extensions ruled out. All the patients underwent total excision of the lesion. During surgery the lesions had hair and calcified portions and one of the swelling showed rudimentary teeth. There was some erosion of the outer table in one case (the young man) but there was no breach of the dinner table in any of the cases. The histopathological report in all cases was dermoid cyst.

\section{Discussion}

Dermoid cysts in the head and neck are usually considered

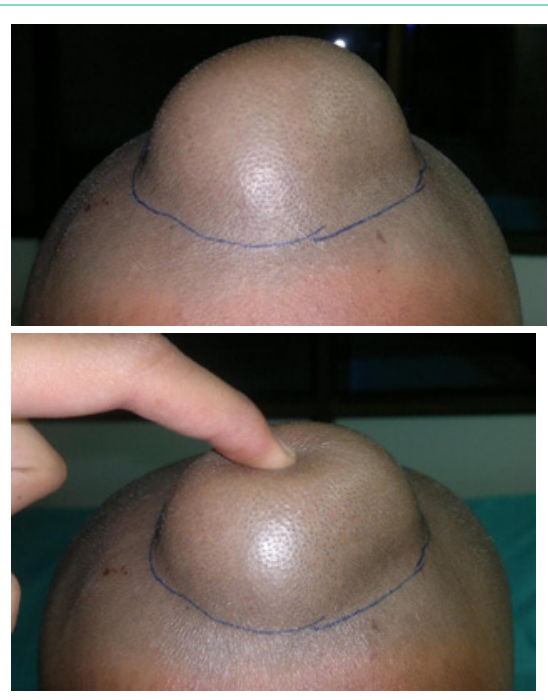

Figure 1: Photograph of one male patient showing the dermoid cyst.

congenital lesions. But occasionally these lesions have been identified in adults also. The importance of dermoids in the scalp is the potential for intracranial extension. Here we describe three adults with histologically proved dermoid cysts in the anterior fontanelle region without any intracranial extension.

De Carvalho and others [3] presented 7 patients aged 3 months to 16 years with cystic lesions of the anterior fontanelle. They were detected at birth and were progressive in size but asymptomatic. All patients underwent removal of the lesion. Ojikutu and Mordi [2] described congenital inclusion dermoid cysts over the region of the anterior fontanelle in two adult Nigerians. Both were seen at birth but were not treated till adult life. There was no intracranial extension in both. Histopathologically both were confirmed as dermoid cysts. Surgical excision was curative. deCastro and others [4] also presented a 23 year old man with a scalp swelling at the region of the anterior fontanelle without any neurological issues. CT scan did not show any intracranial extension. The lesion was excised in total with very good result. The lesion was soft cystic containing a greenish viscous liquid with hair. Chaudhary et al. [5] described 21 children with congenital inclusion cysts of the subgaleal space. A majority of them were in the anterior fontanelle. The cysts were reported as dermoid/ epidermoid cysts. There have been many other studies on 

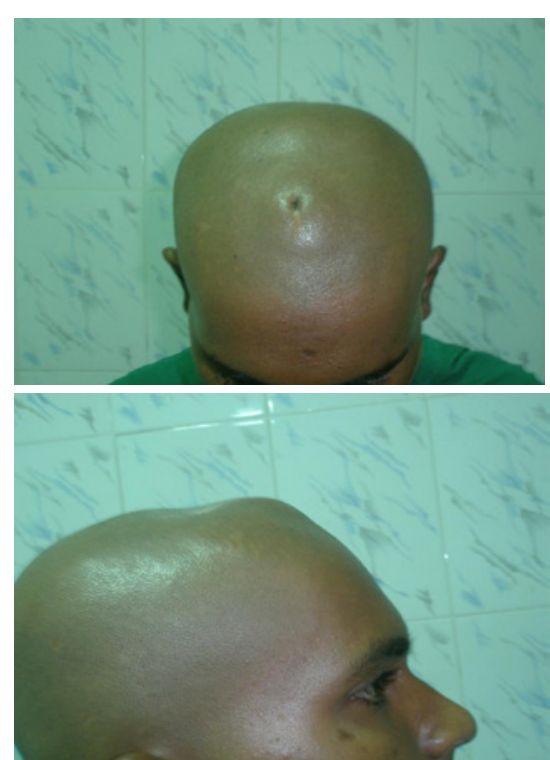

Figure 2: Photograph of another male patient showing the dermoid cyst with punctum.

dermoids [6,7] over the anterior fonanelle with similar conclusions. Reissis and coworkers [8] studied the histology of 16 craniofacial cysts and concluded that histological properties of dermoid cysts are conserved between craniofacial sites (periorbital, nasal, scalp, and postauricular). This reflects the consistency of ectodermal inclusion during early embryological development, which is independent of specific craniofacial site or surrounding anatomical structures.

In our study also all the patients had neurologically asymptomatic lesions without any intracranial extension. All the lesions were confirmed to be dermoids histopatholgically. All the lesions were excised totally without problems. The importance of these lesions for the surgeon is that these can mimic other pathologies like encephalocoels or meningocoels and so CT scan/MRI are a must to rule out the pathology as well as any intracranial extension before any surgical intervention. The existence of this entity is especially useful for the trainee surgeons and neurosurgeons.

\section{Conclusion}

Inclusion dermoid cysts of the anterior fontanel scalp are definite pathologies. However other lesions like encephalocoel need to be kept as differential diagnosis and the patient should undergo radiology accordingly.

Informed consent was obtained from all the three patients included in this study. This included consent for putting up their photographs.

\section{References}

1. Wood J, Couture D, David LR. Midline dermoid cyst resulting in frontal bone erosion. J Craniofac Surg. 2012; 23: 131-134.

2. Ojikutu NA, Mordi VP. Congenital inclusion dermoid cyst located over the region of the anterior fontanel in adult Nigerians: report of two cases. J Neurosurg. 1980; 52: 724-727.

3. de Carvalho GT, Fagundes-Pereyra WJ, Marques JA, Dantas FL, de Sousa AA. Congenital inclusion cysts of the anterior fontanelle. Surg Neurol. 2001; 56: $400-405$.

4. de Castro RAG, Filho ASR, de Silva VV. Dermoid cysts of the anterior fontanelle in adults: Case report. Arq Neuropsiquiatr. 2007; 65: 170-172.

5. Chaudhari AB, Ladapo F, Mordi VPN, Choudhury KJ, Naseem A. Congenital inclusion cyst of the subgaleal space. J Neurosurg. 1982; 56: 540 -544.

6. Sinclair RD, Darley C, Dawber RP. Congenital inclusion dermoid cysts of the scalp. Australas J Dermatol. 1992; 33: 135-140.

7. Tateshima S, Numoto RT, Abe S, Yasue M, Abe T. Rapidly enlarging dermoid cyst over the anterior fontanel: a case report and review of the literature. Childs Nerv Syst. 2000; 16: 875-878.

8. Reissis D, Pfaff MJ, Patel A, Steinbacher DM. Craniofacial dermoid cysts: histological analysis and inter-site comparison. Yale J Biol Med. 2014; 87: 349-357.
Austin J Surg - Volume 4 Issue 4 - 2017

ISSN : 2381-9030 | www.austinpublishinggroup.com

Ramnarayan et al. () All rights are reserved
Citation: Ramnarayan R and Dharmendra KR. Dermoid Cysts of the Anterior Fontanel in Adults. Austin J Surg. 2017; 4(4): 1110 